\title{
Brace treatment in juvenile idiopathic scoliosis: a prospective study in accordance with the SRS criteria for bracing studies - SOSORT award 2013 winner
}

\author{
Angelo G Aulisa ${ }^{1 *}$, Vincenzo Guzzanti ${ }^{1,2}$, Emanuele Marzetti ${ }^{3}$, Marco Giordano ${ }^{1}$, Francesco Falciglia ${ }^{1}$
} and Lorenzo Aulisa ${ }^{3}$

\begin{abstract}
Background: The Juvenile idiopathic scoliosis by age of onset, severity and evolutivity is source of great doubts concerning the purpose and use of conservative treatment. The different clinical experiences leave unsolved the question that arises in applying a conservative treatment when the patients are effectively forward a long growing period, in scoliosis characterized by inevitable evolutivity. The purpose of the present prospective study was to determine the effectiveness of conservative treatment in Juvenile idiopathic scoliosis.

Methods: From 1238 patients treated for idiopathic scoliosis between 1995 and 2012 fulfill the inclusion criteria 163 patients treated with PASB, Lyon brace and Milwaukee. Of these, 113 patients had a definite outcome, 27 have abandoned treatment e 23 are still in treatment. The minimum follow-up was 24 months. Radiographs were used to estimate the curve magnitude (CM) and the torsion of the apical vertebra (TA) at 5 time points: beginning (t1), 6 months after the beginning (t2), intermediate time between $\mathrm{t} 1$ and $\mathrm{t} 4$ ( $\mathrm{t} 3$ ), end of weaning (t4), 2-years minimum follow-up (t5). Three outcomes were distinguished in agreement with SRS criteria: correction, stabilization and progression.

Results: The results from our study showed that of the 113 patients with a definite outcome CM mean value was $29.6 \pm 7.5 \mathrm{SD}$ at $\mathrm{t} 1$ and $16.9 \pm 11.1 \mathrm{SD}$ at t5. TA was $13.5 \pm 5.4 \mathrm{SD}$ at $\mathrm{t} 1$ and $8.5 \pm 5.6$ at t5. The variations between CM t5-t1 and TA t5-t1 were statistically significantly different. Curve correction was accomplished in 88 patients (77.8\%), stabilization was obtained in 18 patients (15.9\%). 7 patients (6.19\%) have a progression and 4 of these were recommended for surgery. Of 26 patients who abandoned the treatment, at the time of abandonment (12.5 age) have achieved curve correction in 19 cases (70.0\%), stabilization in 5 cases (19\%) and progression in 3 cases (11\%). Of these patients, reviewed at the end of growing, four have been operated on.

Conclusions: Our study confirmed that conservative treatment with brace is highly effective in treating juvenile idiopathic scoliosis, in particular most patients reaching a complete curve correction and only $4.9 \%$ of patients need surgery.
\end{abstract}

Keywords: Juvenile idiopathic scoliosis, Scoliosis research society criteria (SRS), PASB brace, Lyon brace, SOSORT guidelines, Conservative treatment

\footnotetext{
* Correspondence: angelogabriele.aulisa@fastwebnet.it

'U.O.C. of Orthopedics and Traumatology, Children's Hospital Bambino Gesù, Institute of Scientific Research, P.zza S. Onofrio 4, 00165 Rome, Italy Full list of author information is available at the end of the article
} 


\section{Background}

The classification of idiopathic scoliosis is based on chronologic criteria related to the age of curve presentation (Terminology Committee of Scoliosis Research Society). The first to divide the idiopathic scoliosis in juvenile (presentation up to 10 years), and adolescent (presentation past 10 years) was Ponseti in 1950 [1]. In 1954, James proposed the distinction of idiopathic scoliosis in infantile, juvenile and adolescent: "Idiopathic scoliosis begins at all ages of childhood but there are three peak periods of onset under the age of three, from five to eight and from ten until the end of growth. For convenience I have called these age groups, infantile, juvenile and adolescent" [2]. Successively, in 1970, James proposed a refinement of the age range: "Some Authors have regarded infantile idiopathic scoliosis as occurring within the first two years of life. I have used the end of the third year to define a curve as being of infantile onset. I have also used the terms juvenile for an onset of scoliosis in the years 4-9 and adolescent scoliosis for the onset of curves between the age of ten and the end of growth." [3]. This classification was subsequently confirmed from Goldstein in 1973 [4]. However, in 2010, the Scoliosis Research Society (SRS) defined juvenile idiopathic scoliosis (JIS) as a scoliosis that is first diagnosed between the ages of 4 and 10 [5].

The incidence of juvenile scoliosis has been reported to be comprised between 7 and 17\% [1,2,5-10]. The discrepancy in incidence data may be attributed to several factors, such as the heterogeneity of the examiners, the different parameters of identification and the size of the sample analyzed. In our series, among 1,238 cases of idiopathic scoliosis who had undergone conservative treatment, JIS was present in 163 subjects (prevalence: $13 \%)$.

The natural course of JIS is much more aggressive than that of adolescent idiopathic scoliosis. Cotrel [11] reported that JIS at the end of growth showed a curve between 50 and $100^{\circ} \mathrm{Cobb}$ in $41 \%$ of patients, and greater than $100^{\circ}$ in $45 \%$ of cases. Duval-Beaupère observed that patients with juvenile scoliosis presented an annual increase in curve magnitude from $4^{\circ}$ to $7^{\circ} \mathrm{Cobb}$ until the prepubertal period, with an average of $23^{\circ} \mathrm{Cobb}$ increase in the following period (puberty - skeletal maturity) [12]. Mannherz [13] found that juvenile curves progress in $70-95 \%$ of patients and about half of this patients will need surgery. Other authors confirmed that juvenile curves of $30^{\circ} \mathrm{Cobb}$ or greater tend to worsen in the absence of treatment, nearly $95 \%$ require surgery $[14,15]$.

In the last years, evidence has shown that bracing is the most effective non-surgical treatment; however, data are limited to adolescent idiopathic scoliosis [16-25]. In the case of JIS, the opportunity and outcomes of conservative treatment are still a matter of debate [26,27]. In most studies, observation is the first treatment in all cases with mild curves $\left(<20^{\circ}\right)$, but treatment should be considered earlier if the in patients showing curve progression and/or with family history of scoliosis. In patients with curves over $25^{\circ}$, treatment is usually indicated due to the high probability of progression. Discrepancies in clinical experiences leave unsolved the question as to whether conservative treatment need to be implemented in juvenile scoliosis $[28,29]$. Actually, several authors believe that conservative treatment does not represent a truly effective option, but only a procrastination of surgery, with the aim of limiting the evolution of the curves and waiting for the right age to intervene $[30,31]$. Nevertheless, some authors have shown a reduction of the incidence of surgery [32,33].

Based on these premises, the present study was undertaken to determine the effects of conservative treatment in JIS.

\section{Methods}

\section{Patients}

This is a prospective study based on ongoing database including 1238 patients treated for idiopathic scoliosis between 1990 and 2012. Inclusion criteria were: age at the beginning of treatment of 4 to 10 years and curve magnitude $\left(\mathrm{C}_{\mathrm{M}}\right) 20^{\circ}-40^{\circ}$ Cobb. Curves between $20^{\circ}$ and $25^{\circ} \mathrm{Cobb}$ degrees were included only in the presence of documented curve progression. Curve progression was assessed on two consecutive X-rays taken at 6-month interval and was defined as an increase greater than $5^{\circ}$ in $C_{M}$ (Cobb's method) [27]. The minimum duration of follow-up was 24 months after the end of treatment.

One-hundred sixty-three patients met the inclusion criteria. Of these, 113 patients had definite outcome, 27 abandoned the treatment, and 23 are currently under treatment.

\section{Bracing}

Patients with thoraco-lumbar and lumbar curves were prescribed with Progressive Action Short Brace (PASB), while Milwaukee or Lyon brace were prescribed in those with thoracic or double curves. All patients were prescribed with full-time bracing (i.e., max 22 hours daily, min 18 hours daily). Daily hours of bracing were defined for each patient according to clinical needs and acceptance. In order to maximize the adherence to treatment, patients were always followed by the same doctor [34]. Furthermore, controls were performed every 2 months until Risser 3, and every 3 months thereafter. Frequent checks allowed to verify and implement compliance establishing an open and friendly relationship with the patients. Close checks were also performed to maximize bracing effectiveness over the time.

Weaning was started when ring-apophysis fusion was seen to begin on a latero-lateral (LL) radiograph view 
[35], which corresponds to a Risser sign 4 or 5 on an antero-posterior (AP) standing radiograph view. Weaning consisted of 2 to 4 hours bracing reduction at 2-month intervals. The curve response to progressive part-time bracing was evaluated on an AP view standing radiograph after the patient had been without bracing for 5 hours. Out-of-brace hours were not reduced and in some cases increased if the curve was not stable.

\section{Endpoints}

For the present study, only the X-ray performed at conventional times were considered: beginning of treatment $\left(t_{1}\right), 4-6$ months after the beginning of treatment $\left(t_{2}\right)$, intermediate time between $t_{1}$ and $t_{4}\left(t_{3}\right)$, end of weaning $\left(t_{4}\right)$, 2-year minimum follow-up from $t_{4}\left(t_{5}\right)$. For each patient, AP and LL view standing X-rays of the whole spine were performed. X-rays before treatment $\left(t_{1}\right)$ as well as those at $t_{4}$ and $t_{5}$ were taken while out of brace. All other radiographic controls were performed with the patient wearing the brace, in order to assess the corrective action of bracing. The first X-ray was obtained at 4-6 months from the beginning of treatment. All other controls were performed once a year. All radiographs were taken at our Institute, at 2-meter distance, on a $36 \times 91 \mathrm{~cm}$ film. The AP view was used to determine the patient's skeletal age (Risser's sign) and to obtain the $C_{M}$ and torsion of the apical vertebra ( $\mathrm{T}_{\mathrm{A}}$ : Perdriolle's method). Measurements were obtained by two independent observers. The end-vertebrae were pre-selected to reduce inter-observer error [27]. Curves were classified according to SRS into thoracic, thoracolumbar, lumbar, and double major. As recommended by the SRS Committee on Bracing and Non-operative Management, outcomes were classified as follows: (1) correction (percentage of patients with $\leq 5^{\circ}$ curve progression), (2) stabilization (percentage of patients with $>-5$ and $<5^{\circ}$ changes in $C_{M}$ ), (3) progression (percentage of patients with $\geq 5^{\circ}$ progression at maturity), and (4) percentage of patients with curves exceeding $45^{\circ}$ at maturity and those who were recommended for or had undergone surgery.

\section{Statistical analysis}

Statistical analysis was performed using the SPSS v.13.0 software (SPSS Inc.; Chicago, IL). For all variables, normality of data was ascertained by the KolmogorovSmirnov's test. Results were analyzed in relation to $C_{M}$ $t_{5}-t_{1}$ at follow-up, assuming that $C_{M} t_{5}-t_{1}$ was not within the Cobb's method \pm 5 range error [27]. Changes in $C_{M}$ and $T_{A}$ over time from $t_{1}$ through $t_{5}$ were assessed via one-way analysis of variance (ANOVA) for repeated measures. Tukey's post-test was applied when needed. The model was adjusted for age, gender, type of curve, and type of bracing. All analyses were performed according to the intention-to-treat principle. Missing data at follow-up were managed according to the Last Observation Carried Forward (LOCF) method. All tests were two-sided, with significance set at $\mathrm{p}<0.05$. Results are presented as mean \pm standard deviation (SD).

\section{Results}

Analyses of patients with a definite outcome

A definite outcome was recorded for 113 patients, 104 females (93\%) and 9 males (7\%), mean age $8.1 \pm 1.2$ years and $16.3 \pm 1.9$ years at $t 1$ and $t 4$, respectively. The mean duration of treatment was $84.2 \pm 16.7$ months, with an average length of follow-up of $56.9 \pm 27.0$ months.

Curve type distribution was as follows: thoracic $(n=32$; $28.3 \%)$, thoraco-lumbar $(\mathrm{n}=30 ; 26.5 \%)$, lumbar $(\mathrm{n}=23$; $20.4 \%)$, and double ( $\mathrm{n}=28 ; 24.8 \%)$.

Changes in $C_{M}$ over time were statistically significant ( $\mathrm{p}$ for trend $<0.0001$ ) [Figure 1], with a mean value of $29.6 \pm 7.5^{\circ} \mathrm{Cobb}$ at $\mathrm{t}_{1}$ and $16.9 \pm 11.1^{\circ} \mathrm{Cobb}$ at $\mathrm{t}_{5}$. A similar pattern was observed for $\mathrm{T}_{\mathrm{A}}(\mathrm{p}$ for trend $<0.0001$ ) [Figure 2], with a mean value of $13.5 \pm 5.4^{\circ}$ Perdriolle at $\mathrm{t}_{1}$ and $8.5 \pm 5.6^{\circ}$ Perdriolle at $\mathrm{t}_{5}$.

Overall, 88 patients (77.8\%) obtained a curve correction, while stabilization was achieved in 18 cases (15.9\%). Curve progression was experienced by 7 patients (6.2\%), 4 of whom were subsequently recommended for surgery. In patients with $C_{M}<30^{\circ}$ at $t_{1}$, the average reduction was $-12.6^{\circ}$ Cobb, while in cases with $C_{M} \geq 30$ at $t_{1}$, the mean correction was $11.8^{\circ} \mathrm{Cobb}$. As for the curve type, patients with lumbar curves obtained an average correction of $14.7^{\circ}$ Cobb [Figure 3], whereas a $8.0^{\circ}$ Cobb decrease was observed in cases with thoraco-lumbar curves and $10.0^{\circ}$ Cobb in those with thoracic curves [Figure 4]. Finally, patients with double curves experienced an average $12.5^{\circ}$ Cobb reduction.

Treatment outcomes according to $\mathrm{C}_{\mathrm{M}}$ at baseline and curve type are shown in Table 1.

\section{Analyses of patients who abandoned the treatment}

Twenty-seven patients abandoned the treatment, 26 females (96\%) and 1 male (4\%), mean age: 8.0 years at $t_{1}$ and 12.5 years at the time of discontinuation.

$\mathrm{C}_{\mathrm{M}}$ was $27.9 \pm 6.9^{\circ} \mathrm{Cobb}$ at $\mathrm{t}_{1}$ and $17.3 \pm 8.4^{\circ} \mathrm{Cobb}$ at the time of bracing discontinuation, with a mean correction of $-10.6^{\circ}$. Curve correction was observed in 19 cases $(70 \%)$, stabilization in 5 patients $(19 \%)$, and progression in 3 patients (11\%). Among 18 patients who were recontacted at the end of growth, 14 showed a progression of $12,7^{\circ} \mathrm{Cobb}$ and 4 had undergone surgery.

\section{Discussion}

The main objective of the present study was determine the effects of conservative treatment in JIS through a prospective approach. The study was conducted according to the SRS Committee criteria and the guidelines on 


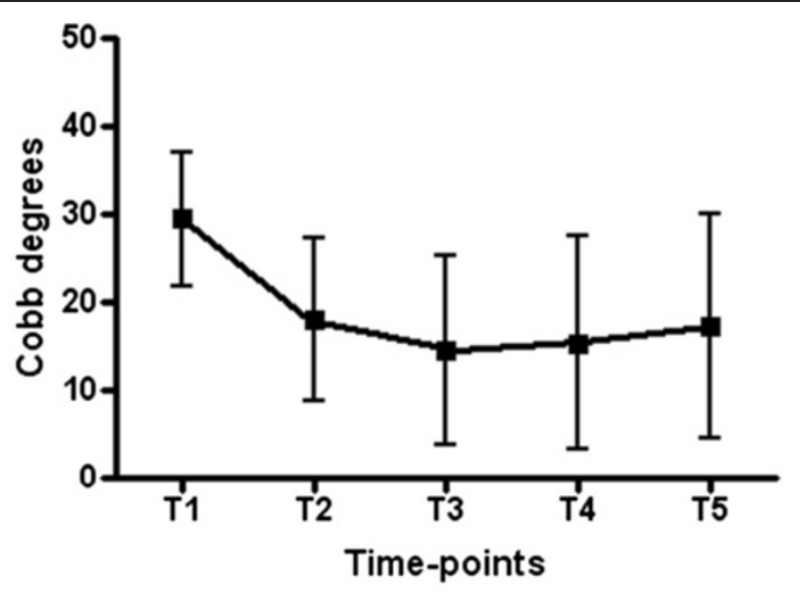

\begin{tabular}{|l|r|c|c|c|}
\hline Tukey's Multiple Comparison Test & Mean Diff. & $q$ & $\mathrm{P}$ value & $95 \% \mathrm{Cl}$ of diff \\
\hline T1 vs T2 & 11,35 & $22,71 \mathrm{P}<0.001$ & 9.395 to 13.30 \\
\hline T1 vs T3 & 14,96 & $29,94 \mathrm{P}<0.001$ & 13.01 to 16.92 \\
\hline T1 vs T4 & 14,07 & $28,16 \mathrm{P}<0.001$ & 12.12 to 16.03 \\
\hline T1 vs T5 & 12,18 & $24,38 \mathrm{P}<0.001$ & 10.23 to 14.14 \\
\hline T2 vs T3 & 3,613 & $7,23 \mathrm{P}<0.001$ & 1.659 to 5.567 \\
\hline T2 vs T4 & 2,723 & $5,448 \mathrm{P}<0.01$ & 0.7686 to 4.677 \\
\hline T2 vs T5 & 0,8361 & $1,673 \mathrm{P}>0.05$ & -1.118 to 2.790 \\
\hline T3 vs T4 & $-0,8908$ & $1,782 \mathrm{P}>0.05$ & -2.845 to 1.063 \\
\hline T3 vs T5 & $-2,777$ & $5,557 \mathrm{P}<0.01$ & -4.731 to -0.8233 \\
\hline T4 vs T5 & $-1,887$ & $3,775 \mathrm{P}>0.05$ & -3.841 to 0.06749 \\
\hline
\end{tabular}

Figure 1 Changes in CM over time in the whole study sample $(n=113)$.

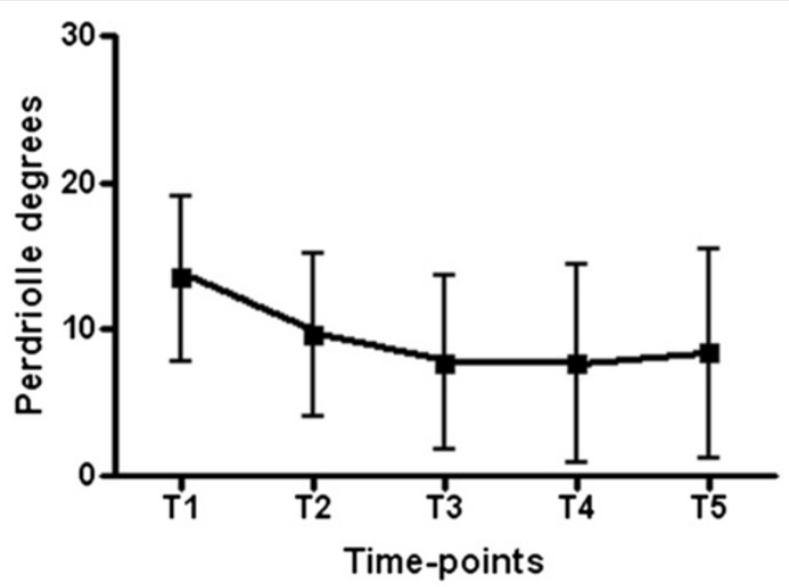

\begin{tabular}{|l|r|r|l|l|}
\hline Tukey's Multiple Comparison Test & Mean Diff. & $\mathrm{q}$ & $\mathrm{P}$ value & $\mathbf{9 5 \%} \mathrm{Cl}$ of diff \\
\hline T1 vs T2 & 3,836 & $16,79 \mathrm{P}<0.001$ & 2.942 to 4.730 \\
\hline T1 vs T3 & 5,744 & $25,13 \mathrm{P}<0.001$ & 4.850 to 6.638 \\
\hline T1 vs T4 & 5,828 & $25,5 \mathrm{P}<0.001$ & 4.934 to 6.722 \\
\hline T1 vs T5 & 5,102 & $22,32 \mathrm{P}<0.001$ & 4.208 to 5.996 \\
\hline T2 vs T3 & 1,907 & $8,346 \mathrm{P}<0.001$ & 1.013 to 2.801 \\
\hline T2 vs T4 & 1,991 & $8,714 \mathrm{P}<0.001$ & 1.097 to 2.886 \\
\hline T2 vs T5 & 1,266 & $5,539 \mathrm{P}<0.01$ & 0.3719 to 2.160 \\
\hline T3 vs T4 & 0,08404 & $0,3677 \mathrm{P}>0.05$ & -0.8100 to 0.9781 \\
\hline T3 vs T5 & $-0,6415$ & $2,807 \mathrm{P}>0.05$ & -1.536 to 0.2525 \\
\hline T4 vs T5 & $-0,7255$ & $3,175 \mathrm{P}>0.05$ & -1.620 to 0.1685 \\
\hline
\end{tabular}

Figure 2 Changes in TA over time in the whole study sample $(n=113)$. 


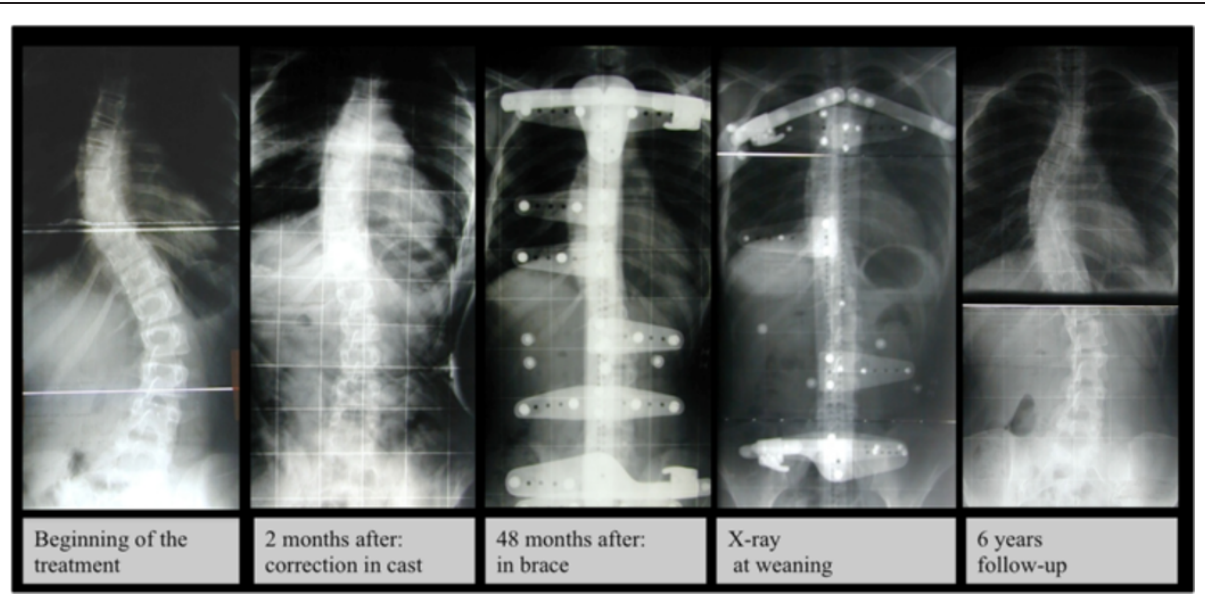

Figure 3 This is a case with a thoracic curve treated with Lyon Brace; Cobb degrees value was $40^{\circ}$ at beginning of treatment and $24^{\circ}$ at 6 years of follow-up.

standard of management of idiopathic scoliosis with corrective braces in everyday clinics and in clinical research proposed by the Society on Scoliosis Orthopaedic and Rehabilitation Treatment (SOSORT) [24,34]. Analyses of our case series revealed that the large majority of patients with a definite outcome (82.5\%) obtained a curve correction after brace treatment, whereas a curve stabilization was accomplished in $15.9 \%$ of cases. Only 4 patients $(3.5 \%)$ were subsequently recommended for surgery during the follow-up. Taken as a whole, the current findings together with our previous observations suggest that the brace treatment is an effective option in JIS.

In the literature there are very few publications that have evaluated the effects of conservative treatment in JIS patients taking the outcome into account. The success rate of orthotic programs in the management of JIS is variable among the different authors, with conservative treatment mainly centered at slowing/stopping the progression of the curve and avoiding or delaying spine fusion. Kahanovitz [36] reported an excellent prognosis with part-time bracing for smaller curves and a poor prognosis in patients with greater Cobb angles, all of whom eventually needed surgery. Tolo and Gillespie [37] found that only $27.2 \%$ $(16 / 59)$ of their patients treated with the Milwaukee brace needed surgery. Similar results were reported by Dabney and Browen [38], with $33 \%$ of surgery recommendations. Other authors have reported much higher percentages of patients who needed surgery despite bracing. For instance, Figueiredo and James [39] reported a $62 \%$ incidence of surgery in patients treated with a modified Milwaukee brace, Mannherz [13] reported 80\%, and McMaster 87\% [10]. In a recent paper, Jarvis [32] highlighted the difficult in comparing the results of the various studies because they involve patients with different characteristics, non standard indications for surgery, which varies from $19 \%$ to $87 \%$, and outcome analysis. Moreover, he showed that patients

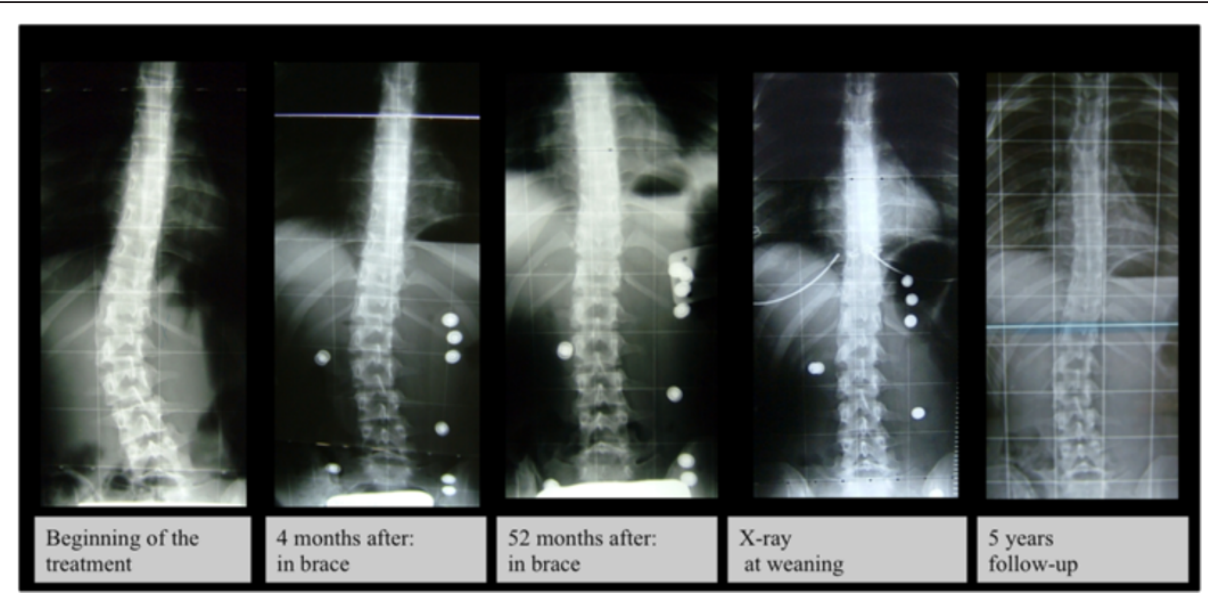

Figure 4 This is a case with a lumbar curve treated with PASB Brace; Cobb degrees value was $29^{\circ}$ at beginning of treatment and $8^{\circ}$ at 5 years of follow-up. 
Table 1 Treatment outcome according to curve severity at baseline and type of curve

\begin{tabular}{|c|c|c|c|c|}
\hline & Curve correction (n, \%) & Curve stabilization (n, \%) & Curve progression $(n, \%)$ & Surgery referral $(n, \%)$ \\
\hline \multicolumn{5}{|l|}{ Curve severity at $t_{1}$} \\
\hline$<30^{\circ} \operatorname{Cobb}(\mathrm{n}=59)$ & 49(83\%) & 7 & 2 & $1(1.6 \%)$ \\
\hline$\geq 30^{\circ} \mathrm{Cobb}(\mathrm{n}=54)$ & $39(72.2 \%)$ & 11 & 5 & $3(5.5 \%)$ \\
\hline \multicolumn{5}{|l|}{ Curve type } \\
\hline Lumbar $(n=23)$ & $23(100 \%)$ & $0(--)$ & $0(--)$ & $0(--)$ \\
\hline Thoraco-lumbar $(n=30)$ & $26(86.7 \%)$ & $4(13.3 \%)$ & $0(--)$ & $0(--)$ \\
\hline Thoracic $(n=32)$ & $21(65.6 \%)$ & 7 (21.9\%) & $4(12.5 \%)$ & $3(9.4 \%)$ \\
\hline Double $(n=28)$ & 18 & 7 & 3 & $1(3.6 \%)$ \\
\hline
\end{tabular}

treated with part-time Charleston bracing obtained correction in $52 \%$ of cases and underwent surgery in $30 \%$.

To date, the only prospective study adopting the SRS criteria for outcome evaluation in juvenile scoliosis has been performed in patients treated with Dynamic SpineCor bracing [33]. Fifty-seven\% of cases reached a curve correction or stabilization. However, $37 \%$ of patients needed surgical fusion while receiving treatment $(26.3 \%$ with curves $<25^{\circ}$ and $51.8 \%$ with curves $>25^{\circ}$ ).

Comparing our series to the findings reported above, we showed $75 \%$ of correction and only $5 \%$ of surgery in a larger sample of patients and with different braces. Furthermore, significant correction was detected both for $C_{M}$ and $T_{A}$, demonstrating the efficacy of treatment on both parameters.

The greatest correction was observed in cases treated with PASB (lumbar and thoraco-lumbar curves), with none of the patients showing curve progression $\left(>5^{\circ}\right)$ at follow-up. In addition, correction was achieved early during treatment. This might have occurred because in the initial phase bracing acts mostly on the elastic component of the curve, leading to an early, substantial correction. However, derotation and vertebral remodeling proceed during the entire course of treatment, ensuring further curve correction and its maintenance over time.

With regard to curve severity, it is worth noting that patients with curves under $30^{\circ}$ obtained a correction in $83 \%$ of cases (incidence of surgery: $1.6 \%$ ), while curves over $30^{\circ}$ reached a correction in $72.2 \%$ of cases, with surgery recommended in $5.5 \%$ of patients. These results cannot be explained only by mechanical aspects. Indeed, the response of the scoliotic spine to the actions exerted by the orthosis is determined by two factors: the ability to remodel the vertebrae (in accordance with the law of Hueter-Volkman) and the suitability of visco-elastic structures to respond adequately to the action of bracing. Any mechanical strain appears inadequate to promote the remodeling process without an adequate visco-elastic response of the structures involved. Therefore, the discs included in the scoliotic curve must be able to work in the field of linear elasticity. The state of disc's hysteresis, in fact, would make it unable to transmit effective actions for recovery of the deformity $[40,41]$. Hence, the greater the rotation of the curve, the less the capacity of its correction. Therefore the early diagnosis of scoliosis is very important and to facilitate early administration of conservative treatments we can use school screening that is predictive and sensitive tool with a low referral rate $[42,43]$.

About the patients who abandoned the treatment the results showed a progression of curve, at the time of discontinuation, only in the $11 \%$ of cases. Therefore, were not the results to send away the patient but, probably, the trouble of a long term treatment. In particular the failure rate of treatment including the dropouts is $24 \%$ but the surgical rate is $12 \%$.

\section{Conclusions}

The results obtained in this prospective study clearly show that brace treatment (PASB, Lyon and Milwaukee) can alter the natural history of JIS and that the correction appears to be maintained over the long term. The treatment appears to be more effective with curves under $30^{\circ}$ (incidence of surgery: $1.6 \%$ ) than curves over $30^{\circ}$ (incidence of surgery: 5.5\%) but compared to the natural history of disease both are better. Moreover these results confirm that the adoption of conservative approaches based on the SOSORT and SRS guidelines produce better results. Nonetheless, these results highlight the necessity for new studies to evaluate the effectiveness of conservative treatment in Juvenile idiopathic scoliosis in curves over 40 degrees.

\section{Abbreviations}

JIS: Juvenile idiopathic scoliosis; SRS: Scoliosis Research Society; PASB: Progressive action short brace; CM: Curve magnitude; LL: Latero-lateral; AP: Antero-posterior; $\mathrm{T}_{\mathrm{A}}$ : Torsion of the apical vertebra.

\section{Competing interests}

The authors declare that they have no competing interests.

\section{Authors' contributions}

All authors contributed equally to this work, all authors read and approved the final manuscript. 


\section{Acknowledgements}

The Authors further represents that the article is original, that it is not under consideration by another journal, and that it has not been previously published. This assignment is to take effect only if the work is published in the Journal.

\section{Author details}

${ }^{1}$ U.O.C. of Orthopedics and Traumatology, Children's Hospital Bambino Gesù, Institute of Scientific Research, P.zza S. Onofrio 4, 00165 Rome, Italy. ${ }^{2}$ University of Cassino, Cassino, FR 03043, Italy. ${ }^{3}$ Department of Orthopedics, University Hospital "Agostino Gemelli", Catholic University of the Sacred Heart School of Medicine, Rome 00168, Italy.

\section{Received: 9 February 2014 Accepted: 11 April 2014}

Published: 23 April 2014

\section{References}

1. Ponseti IV, Friedman B: Prognosis in idiopathic scoliosis. I Bone Joint Surg [Am] 1950, 32:381-395.

2. James JP: Idiopathic scoliosis. J Bone Joint Surg 1954, 36-B:36-49.

3. James JIP: The etiology of scoliosis. J Bone Joint Surg (Br) 1970, 52:410-419.

4. Goldstein LA, Waugh TR: Classification and terminology of scoliosis. Clin Orthop 1973, 93:10-22

5. Scoliosis Research Society: Juvenile scoliosis; 2010. http://www.srs.org/ professionals/conditions_and_treatment/juvenile_scoliosis/index.htm.

6. Wynne-Davies R: Familial (idiopathic) scoliosis. J Bone Joint Surg 1968, 50-B:24-30.

7. Moe JH, Kettleson DN: Idiopathic scoliosis. J Bone Joint Surg 1970, 52-A:1509-1533.

8. Riseborough EJ, Wynne-Davies R: A genetic survey of idiopathic scoliosis in Boston, Massachusetts. J Bone Joint Surg Am 1973, 55:974-982.

9. Keiser RP, Shufflebarger HL: The Milwaukee brace in idiopathic scoliosis: evaluation of 123 completed cases. Clin Orthop Relat Res 1976, 118:19-24

10. McMaster MJ: Infantile idiopathic scoliosis: can it be prevented? J Bone Joint Surg (Br) 1983, 65(5):612-617.

11. Cotrel Y, Morel G, Rey JC: Idiopathic scoliosis. Acta Orthop Belg 1965, 31(5):795-810

12. Duval-Beaupère G, Dubousset J, Queneau P, Grossiord A: Pour une théorie unique de l'évolution des scolioses. Press Méd 1970, 78:1141-1146.

13. Mannherz RE, Betz RR, Clancy M, Steel HH: Juvenile idiopathic scoliosis followed to skeletal maturity. Spine 1988, 13:1087-1090.

14. Winter RB: Spinal deformity. Disorders of the pediatric spine. New York: Raven Press; 1995:309-348.

15. Charles YP Daures JP, De Rosa V, Diméglio A: Progression risk of idiopathic juvenile scoliosis during pubertal growth. Spine (Phila Pa 1976) 2006, 31(17):1933-1942.

16. Aulisa AG, Guzzanti V, Galli M, Perisano C, Falciglia F, Aulisa L: Treatment of thoraco-lumbar curves in adolescent females affected by idiopathic scoliosis with a progressive action short brace (PASB): assessment ofresults according to the SRS committee on bracing and non operative management standardization criteria. Scoliosis 2009, 4:21.

17. Negrini S, Atanasio S, Fusco C, Zaina F: Effectiveness of complete conservative treatment for adolescent idiopathic scoliosis (bracing andexercises) based on SOSORT management criteria: results according to the SRS criteria for bracing studies - SOSORT award 2009 winner. Scoliosis 2009, 4:19.

18. Negrini S, Minozzi S, Bettany-Saltikov J, Zaina F, Chockalingam N, Grivas TB, Kotwicki T, Maruyama T, Romano M, Vasiliadis ES: Braces for idiopathic scoliosis in adolescents. Spine (Phila Pa 1976) 2010, 35(13):1285-1293.

19. Aulisa AG, Guzzanti V, Perisano C, Marzetti E, Menghi A, Giordano M, Aulisa L: Correlation between hump dimensions and curve severity in idiopathic scoliosis before and after conservative treatment. Spine (Phila Pa 1976) 2011, 8:

20. Lange JE, Steen $\mathrm{H}$, Gunderson R, Brox Jl: Long-term results after Boston brace treatment in late-onset juvenile and adolescent idiopathic scoliosis. Scoliosis 2011, 6:18.

21. Negrini S, Negrini F, Fusco C, Zaina F: Idiopathic scoliosis patients with curves more than 45 Cobb degrees refusing surgery can be effectively treated through bracing with curve improvements. Spine J 2011, 11(5):369-380
22. Aulisa AG, Guzzanti V, Perisano C, Marzetti E, Falciglia F, Aulisa L: Treatment of lumbar curves in scoliotic adolescent females with progressive action short brace: a case series based on the scoliosis research society committee criteria. Spine (Phila Pa 1976) 2012, 37(13):786-791.

23. Lee CS, Hwang CJ, Kim DJ, Kim JH, Kim YT, Lee MY, Yoon SJ, Lee DH: Effectiveness of the Charleston night-time bending brace in the treatment of adolescent idiopathic scoliosis. J Pediatr Orthop 2012, 32(4):368-372.

24. Negrini S, Aulisa AG, Aulisa L, Circo AB, De Mauroy JC, Durmala J, Grivas TB, Knott P, Kotwicki T, Maruyama T, Minozzi S, O'Brien JP, Padopoulos D, Rigo M, Rivard CH, Romano M, Wynne JH, Villagrasa M, Weiss HR, Zaina F: 2011 SOSORT guidelines: orthopaedic and rehabilitation treatment of idiopathic scoliosis during growth. Scoliosis 2012, 7(1):3.

25. Weinstein SL, Dolan LA, Wright JG, Dobbs MB: Effects of bracing in adolescents with idiopathic scoliosis. N Engl J Med 2013, 369(16):1512-1521

26. Ceballos T, Ferrer-Torrelles M, Castillo F, Fernandez-Paredese E: Prognosis in infantile idiopathic scoliosis. J Bone Joint Surg 1980, 62-A:863-875.

27. Morrissy RT, Goldsmith GS, Hall EC, Kehl D, Cowie GH: Measurement of the Cobb angle on radiographs of patients who have scoliosis. Evaluation of intrinsic error. J Bone Joint Surg Am 1990, 72(3):320-327.

28. Scott JC, TH E m: The natural history and prognosis of infantile idiopathic scoliosis. J Bone Joint Surg 1955, 37- B:400-413.

29. Walker GF: An evaluation of an external splint for idiopathic structural scoliosis in infancy. J Bone Joint Surg 1965, 47-B:524-525.

30. Wynne-davies R: infantile idiopathic scoliosis. J Bone Joint Surg 1975, 57-b:138-141.

31. MCmaster MJ, Macnicol MF E: the management of progressive infantile idiopathic scoliosis. J Bone Joint Surg 1979, 61-b:36-42.

32. Jarvis J, Garbedian S, Swamy G: Juvenile idiopathic scoliosis: the effectiveness of part-time bracing. Spine (Phila Pa 1976) 2008, 33(10):1074-1078.

33. Coillard $\mathrm{C}$, Circo $\mathrm{AB}$, Rivard $\mathrm{CH}$ : SpineCor treatment for Juvenile Idiopathic Scoliosis: SOSORT award 2010 winner. Scoliosis 2010, 5:25.

34. Richards BS, Bernstein RM, D'Amato CR, Thompson CH: Standardization of criteria for adolescent idiopathic scoliosis brace studies: SRS committee on bracing and nonoperative management. Spine 2005, 30:2068Y2075.

35. Bick EM, Copel JW: The ring apophysis of the human vertebra; contribution to human osteogeny. J Bone Joint Surg Am 1951, 33-A(3):783-787.

36. Kahanovitz N, Levine DB, Lardone J: The part-time Milwaukee brace treatment of juvenile idiopathic scoliosis. Long term follow-up. Clin Orthop Relat Res 1982, 167:145-151.

37. Tolo VT, Gillespie R: The characteristics of juvenile idiopathic scoliosis and results of treatment. J Bone Joint Surg (Br) 1978, 60:181-188.

38. Dabney KW, Browen JR: Juvenile idiopathic scoliosis. Semin Spine Surg 1991, 3:524-530.

39. Figueiredo UM, James Jl: Juvenile idiopathic scoliosis. J Bone Joint Surg (Br) 1981, 63-B(1):61-66.

40. Vinciguerra A, Di Benedetto A, Aulisa L: Sulla determinazione delle caratteristiche elastiche del rachide toracolombare. Minerva Ortop Traumatol 1984, 35:133-138.

41. Aulisa L, Vinciguerra A, Tamburrelli F, Lupparelli S, Di Legge V: Biomechanical analysis of the elastic behaviour of the spine with aging In Research into spinal deformities 1. Edited by SevastiK JA, Diab KM. IOS Press: Amsterdam; 1997:229-231.

42. Leone A, Aulisa A, Perisano C, Re T, Galli M: Advantages of a two-step procedure for school-based scoliosis screening. Radiol Med 2010, 115(2):238-245.

43. Labelle H, Richards SB, De Kleuver M, Grivas TB, Luk KDK, Wong H, Thometz J, Beauséjour M, Turgeon I, Fong DYT: Screening for adolescent idiopathic scoliosis: an information statement by the scoliosis research society international task force. Scoliosis 2013, 8:17.

doi:10.1186/1748-7161-9-3

Cite this article as: Aulisa et al:: Brace treatment in juvenile idiopathic scoliosis: a prospective study in accordance with the SRS criteria for bracing studies - SOSORT award 2013 winner. Scoliosis 2014 9:3. 